\title{
P-0437 Eating glutinous brown rice for 8 weeks improves glycemic control in Japanese patients with diabetes mellitus
}

\section{Yuta Nakamura, Yoshio Nagai, Taiga Nakayama, Yuko Terashima, Satoshi Ishii, Hiroyuki Kato, and Yasushi Tanaka Metabolism and Endocrinology, Internal Medicine, St. Marianna University School of Medicine}

\section{《Background/Aims》}

- Several studies have proved that brown rice (BR) is effective for improving metabolic syndrome ${ }^{1)}$ or preventing diabetes mellitus ${ }^{2)}$. However, it may be difficult for people to continue eating BR due to its taste and texture. We expected that patients might prefer glutinous brown rice (GBR) over BR and continue to eat it in daily life. We reported that eating GBR for one day improved the glucose compared with eating WR or standard BR ${ }^{3}$. However, it was unknown whether eating GBR could maintain improvement of glycemic control for a longer period.

- We evaluated the effect of GBR intake for 8 weeks on glycemic control in outpatients with diabetes mellitus.

\begin{tabular}{|c|c|c|}
\hline \multicolumn{3}{|l|}{ 《Method》 } \\
\hline \multicolumn{3}{|l|}{ n=8 WR (8weeks) } \\
\hline \multicolumn{3}{|l|}{$\mathrm{n}=8$ GBR (8weeks) } \\
\hline $\begin{array}{cr}\text { HbAlc, GA, } & \mathrm{HbA} \\
\text { MMTT } & \mathrm{Ml}\end{array}$ & $\begin{array}{l}\uparrow \\
1 \mathrm{c}, \mathrm{GA}, \\
\mathrm{MTT}\end{array}$ & $\begin{array}{l}\uparrow \\
\text { HbAlc, GA, } \\
\text { MMTT }\end{array}$ \\
\hline \multicolumn{3}{|c|}{ Figure 1. Study protocol } \\
\hline \multicolumn{3}{|c|}{$\langle$ subjects〉 Outpatients with type 2 diabetes. } \\
\hline \multicolumn{3}{|c|}{$\langle$ study design $\rangle$} \\
\hline \multicolumn{3}{|c|}{ This was an open-label randomized crossover study. } \\
\hline \multicolumn{3}{|c|}{ Figure 1 shows an outline of the study protocol. } \\
\hline \multicolumn{3}{|c|}{$\begin{array}{l}\text { A mixed meal tolerance test (MMTT) was performed at } \\
\text { baseline and after } 8 \text { and } 16 \text { weeks of dietary intervention }\end{array}$} \\
\hline \multicolumn{3}{|c|}{ 《Characteristics》 } \\
\hline $\mathrm{n}$ (male/female) & (n) & $12 / 4$ \\
\hline Age & (years) & $64 \pm 8.8$ \\
\hline BMI & $\left(\mathrm{kg} / \mathrm{m}^{2}\right)$ & $25.7 \pm 5.6$ \\
\hline HbA1c & $(\%)$ & $7.5 \pm 0.6$ \\
\hline Glycoalbumin & $(\%)$ & $20.7 \pm 2.6$ \\
\hline 1,5-anhydroglucitol & $(\mu \mathrm{g} / \mathrm{mL})$ & $6.9 \pm 3.1$ \\
\hline BUN & $(\mathrm{mg} / \mathrm{dL})$ & $14.9 \pm 3.7$ \\
\hline Cre & $(\mathrm{mg} / \mathrm{dL})$ & $0.8 \pm 0.2$ \\
\hline eGFR $\quad(\mathrm{mL} / \mathrm{mi}$ & $\left.\mathrm{in} / 1.73 \mathrm{~m}^{2}\right)$ & $76.6 \pm 19.5$ \\
\hline Total Cholesterol & $(\mathrm{mg} / \mathrm{dL})$ & $175.1 \pm 37.2$ \\
\hline LDL Cholesterol & $(\mathrm{mg} / \mathrm{dL})$ & $101.8 \pm 28.9$ \\
\hline HDL Cholesterol & $(\mathrm{mg} / \mathrm{dL})$ & $53.8 \pm 18.6$ \\
\hline Triglycerides & $(\mathrm{mg} / \mathrm{dL})$ & $101.1 \pm 50.5$ \\
\hline Fasting blood glucose & $(\mathrm{mg} / \mathrm{dL})$ & $154.1 \pm 22.9$ \\
\hline Fasting serum C-peptide & $(\mathrm{ng} / \mathrm{mL})$ & $1.0 \pm 0.8$ \\
\hline Diabetes treatment & {$[\%(\mathrm{n})]$} & \\
\hline MDI only & & $37.5(6)$ \\
\hline $\mathrm{MDI}+\mathrm{OHA}$ & & $62.5(10)$ \\
\hline
\end{tabular}

Table 1. Characteristics of the subjects $(n=16)$

Data are the mean $\pm \mathrm{SD}$ or \% (n), BMI; Body mass index, MDI; Multiple daily insulin injections, OHA; oral hypoglycemic agent, eGFR; estimated glomerular filtration rat
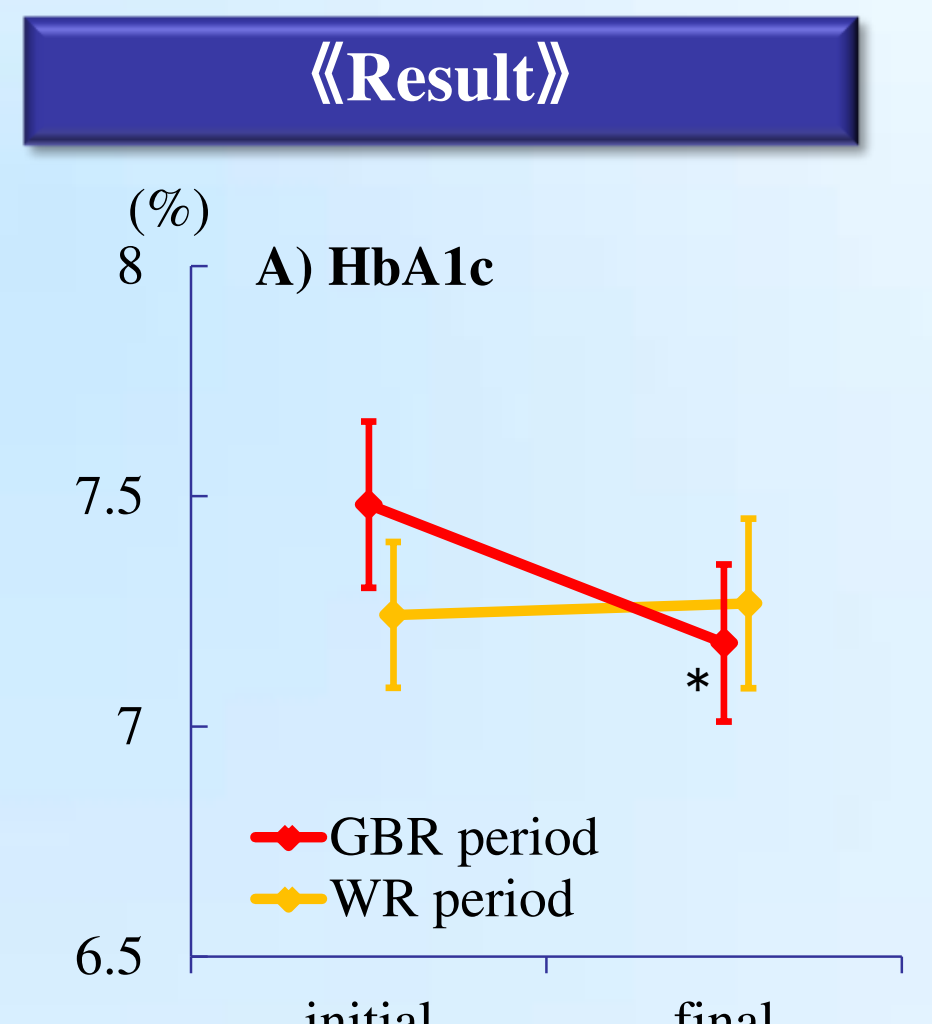

$22^{(\%)} \quad$ B) $\mathbf{~ G A}$

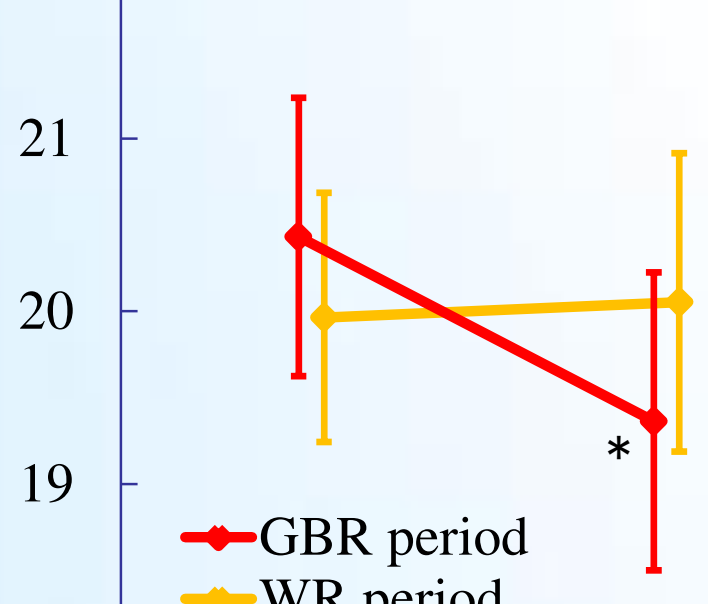

18

initial

final

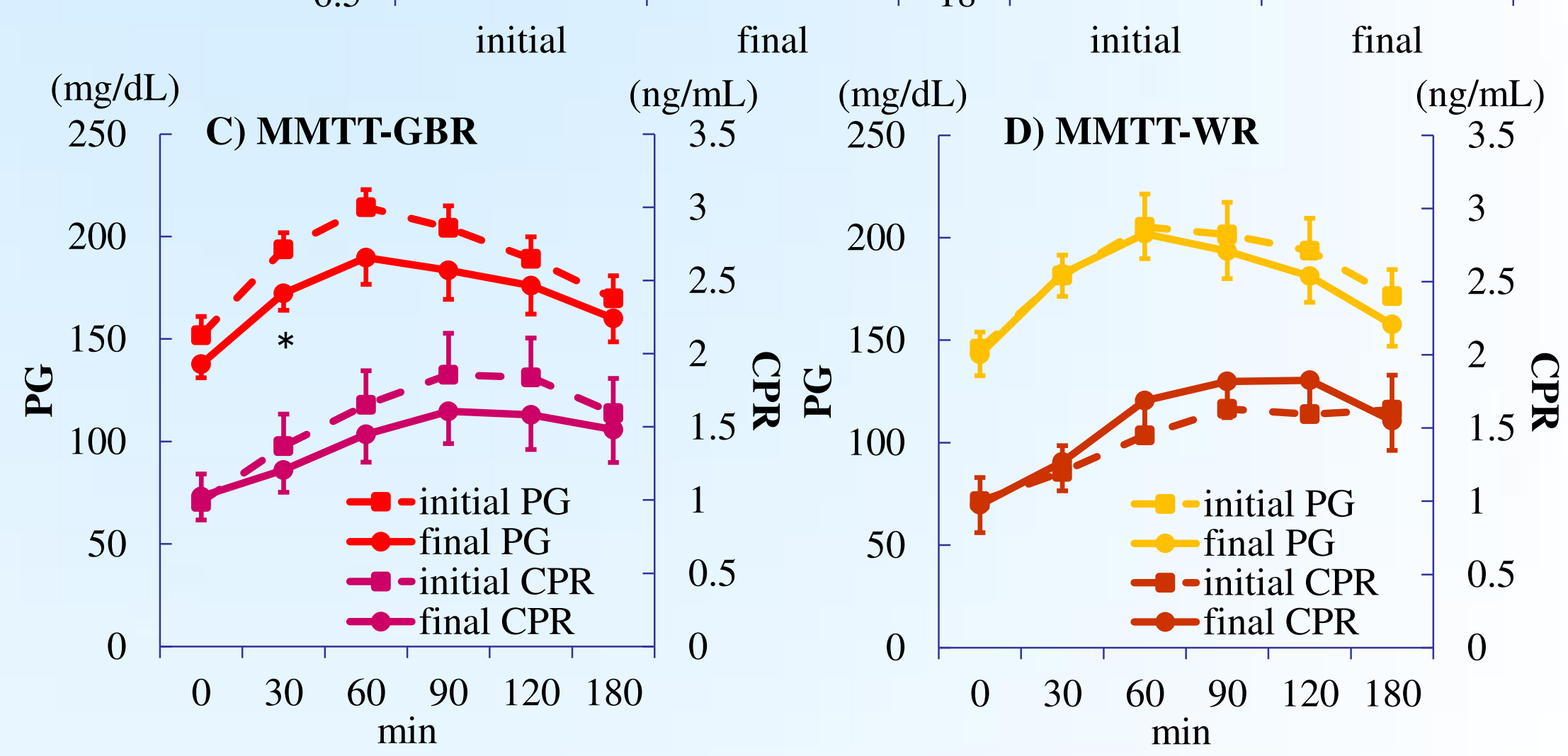

Figure 2. Changes of $\mathrm{HbAlc}(\mathrm{A})$ and glycoalbumin (B) during the GBR period and the WR period. Profile of plasma glucose and C-peptide $(\mathrm{C}, \mathrm{D})$ during the mixed meal tolerance test. Data are expressed as the mean \pm s.e. $* \mathrm{p}<0.05$ vs initial.
$(\%)$
$8.5(\%)$
E) active GLP-1

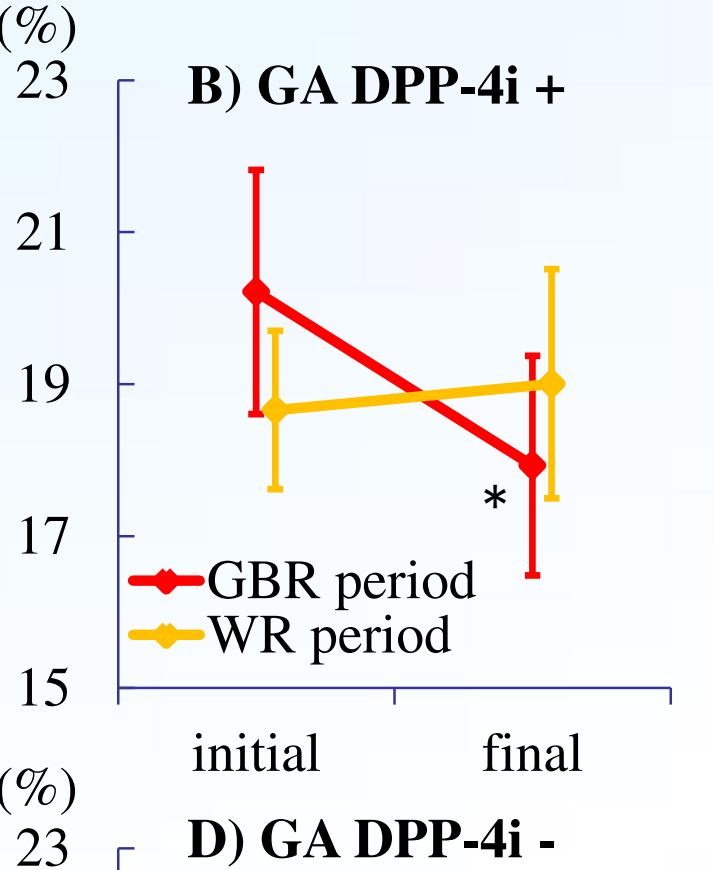

8.5 A) HbA1c DPP-4i +

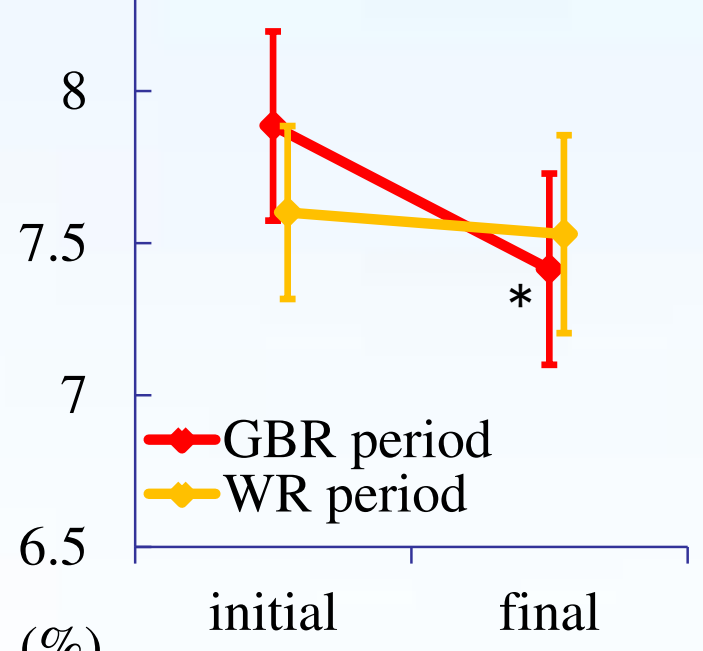

$\begin{array}{lcc}(\%) & \text { initial final } \\ 8.5 & \text { C) HbA1c DPP-4i - }\end{array}$

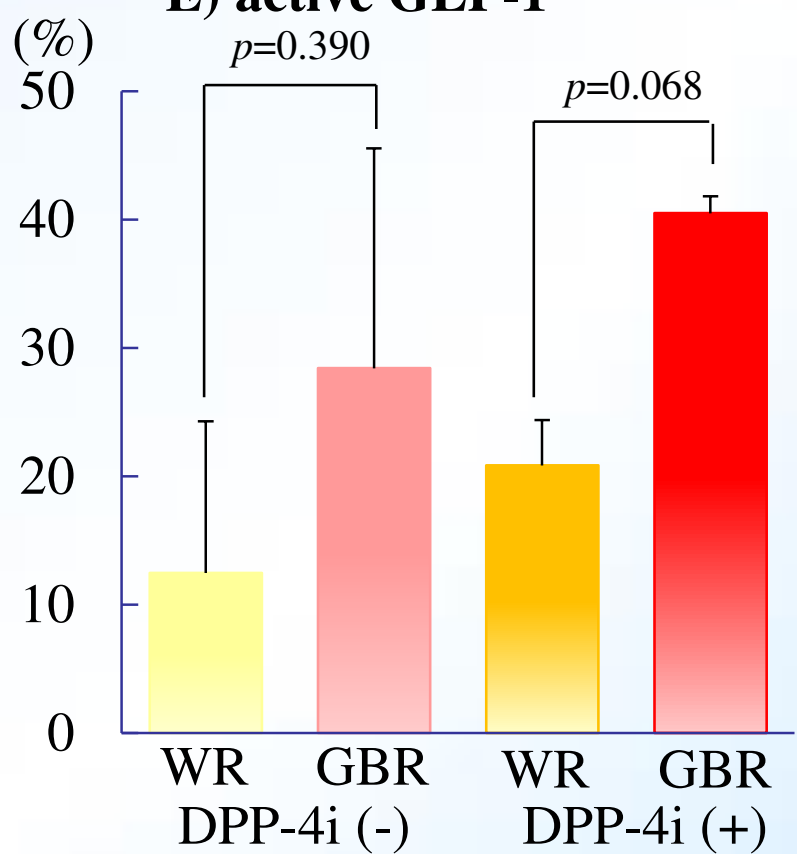

8.5 C) HbA1c DPP-4i - 23 D) GA DPP-4i -

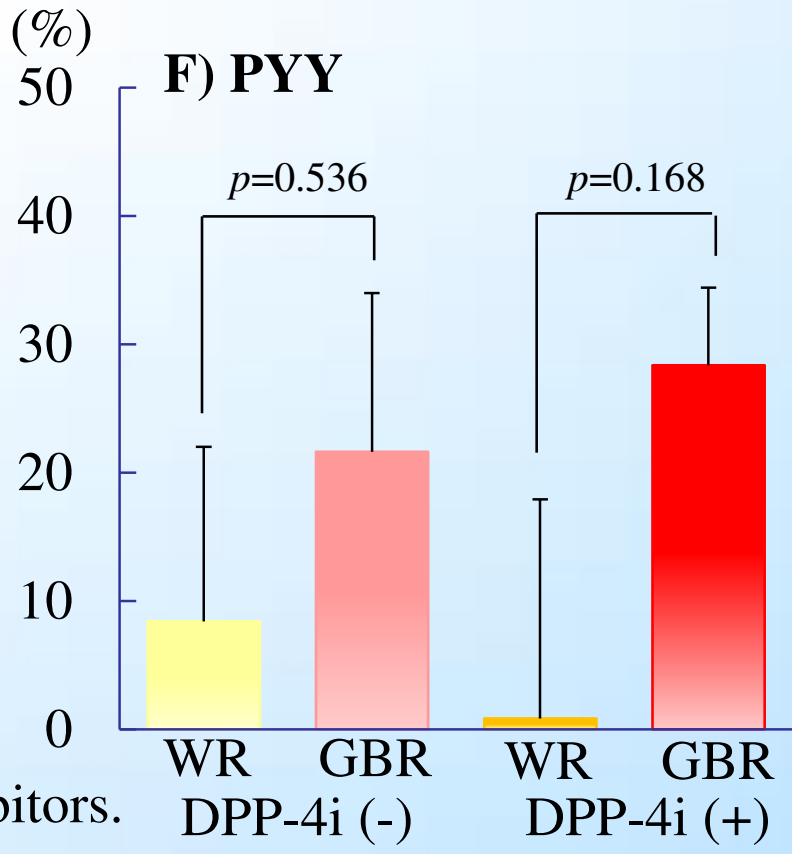

Figure 3. Changes of HbAlc $(\mathrm{A}, \mathrm{C})$ and glycoalbumin $(\mathrm{B}, \mathrm{D})$
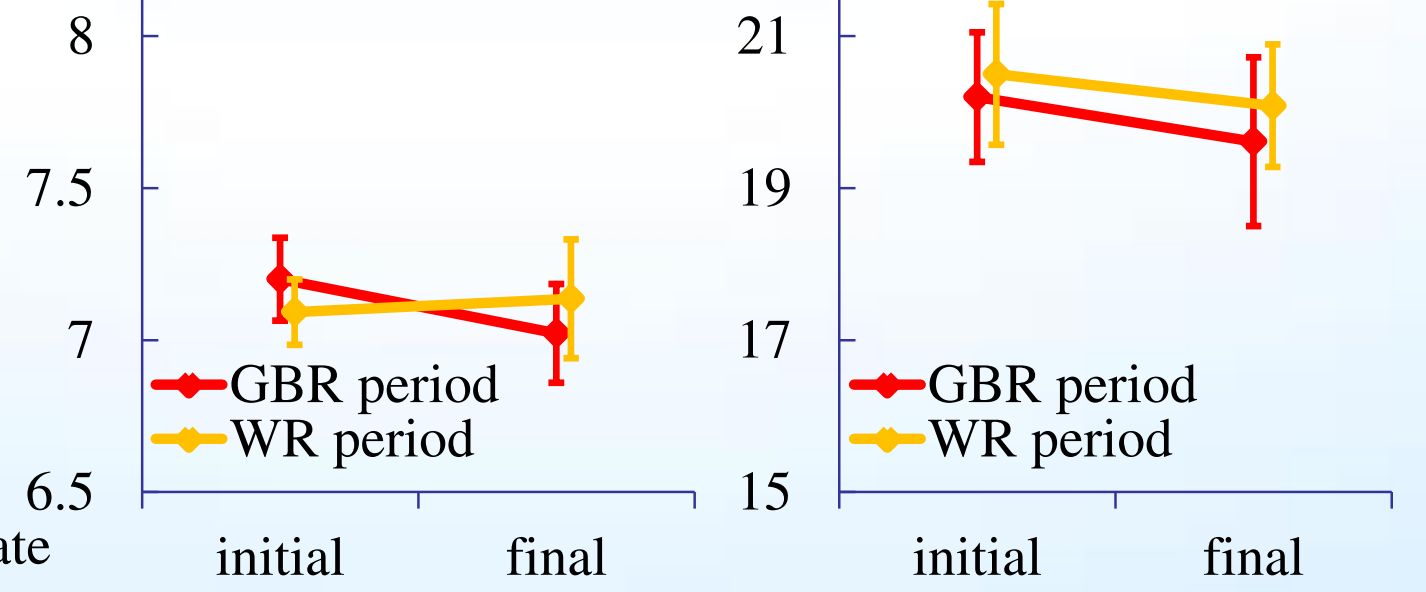

in patients with $(\mathrm{A}, \mathrm{B})$ or without $(\mathrm{C}, \mathrm{D})$ concomitant use of DPP-4 inhibitors Changes of active GLP-1 (E), PYY (F).

\section{《Discussion》 \\ GBR contains some substances, such as magnesium ${ }^{4)}$ and $\gamma$-oryzanol ${ }^{5)}$ that may improve glycemic control.}

GBR might stimulate GLP-1 secretion secondary to an increase of short chain fatty acids (SCFAs) produced from dietary fiber by the gut microbiota. A previous study showed that eating whole grains for 6 weeks improved gut microbiota and increased SCFA levels ${ }^{6}$. It was also reported that the SCFA propionate stimulates secretion of GLP-1 and PYY via free fatty acid receptor 2 in rodents ${ }^{7}$.

GBR has a higher content of dietary fiber $(3.2 \mathrm{~g} / 100 \mathrm{~g})$ compared with WR $(0.2 \mathrm{~g} / 100 \mathrm{~g})$.

Therefore, DPP4-inhibitor therapy could have an additive effect on the benefits of GBR. 